\title{
Cognitive factors in the concurrent differential conditioning of eyelid and skin conductance responses
}

\author{
PAUL E. BAER and MARCUS J. FUHRER \\ Baylor College of Medicine, Houston, Texas 77030
}

\begin{abstract}
The objectives of the study were to (1) determine if differential conditioning of eyelid responses occurs only among subjects who accurately report knowledge of the CS-UCS relations, (2) assess whether differentially conditioned eyelid responding occurs only after the initial accurate intertrial report, and (3) explore characteristics of differentially conditioned skin conductance responses (SCRs) obtained in an eyelid conditioning paradigm, with special attention to whether eyelid and SCR conditioning are similarly related to the subjects' knowledge of the stimulus relations. Fifty-one male subjects were administered 80 differential eyelid conditioning trials, the CSs consisting of the 1,200-msec illumination of slides containing either grammatically correct or grammatically incorrect phrases. Significant differential SCR and eyelid conditioning was obtained for both $\mathrm{V}$ - and $\mathrm{C}$-form eyelid responders, but only for subjects who accurately reported the CS-UCS relations. The initial appearance of SCR and eyelid differentiation was related within the trial sequence to subjects' recognition of the stimulus relations. Eyelid and SCR conditioning were related similarly to knowledge of the stimulus relations, the exception being that subjects who recognized the stimulus relations late in the trial sequence did not develop reliable eyelid differentiation.
\end{abstract}

Considerable evidence exists to support the view that awareness of the CS-UCS relations is necessary but not sufficient for the acquisition of differentially conditioned autonomic responses (Dawson \& Furedy, 1976). A positive relationship between knowledge of the stimulus relations and differential conditioning has been obtained repeatedly, principally for skin conductance responses (SCRs) (Baer \& Fuhrer, 1968; Dawson \& Biferno, 1973; Fuhrer \& Baer, 1969), but for vasomotor responses as well (Baer \& Fuhrer, 1970; Shean, 1968).

To extend the generality of the awareness-conditioning relationship, it is important to establish whether that relationship also applies to the conditioning of eyelid responses, since so much of the research literature on human classical conditioning has focused upon this response modality. In an early, isolated study, Hilgard, Campbell, and Sears (1937) reported a tendency for differential eyelid conditioning and awareness to be positively related. Kimble (1962) asserted that subjects undergoing eyelid conditioning typically become aware of the CS-UCS relations and that this awareness develops very rapidly during the course of acquisition trials. No data were offered, however, in support of this claim. Nelson and Ross (1974) have reported that differential conditioning in the context of a masking task was

This research was supported in part by National Institute of Mental Health Grant MH-12908. Requests for reprints should be addressed to Paul E. Baer, Department of Psychiatry, Baylor College of Medicine, 1200 Moursund Ave., Houston, Texas 77030. limited to subgroups of subjects able to recognize and report the CS-UCS relations that masking was intended to obscure.

Particularly relevant to the present study is the report of Perry, Grant, and Schwartz (1977). Using semantic $\mathrm{CSs}$ in an otherwise conventional differential eyelid paradigm, they found that only the subgroup of subjects who correctly stated the CS-UCS relations following the experiment achieved differential conditioning and that this outcome obtained for both $\mathrm{V}$ - and $\mathrm{C}$-form responders. The topography of the conditioned eyelid response is either voluntary (V) in form, with large magnitude and rapidly recruited closure, or conditioned (C) in form, with small magnitude and slowly recruited closure. According to Grant (1973), a critical feature of this experiment was that enough unaware subjects were yielded to permit the relations between awareness and differential eyelid conditioning to be assessed.

The intention of the present study was threefold. The first aim was to attempt to replicate in part the findings of Perry et al. (1977), including examination of $\mathrm{V}$ - and $\mathrm{C}$-form responders. The second was to extend the investigation of the significance of subjects' knowledge of the CS-UCS relations not only by classifying individuals as aware or nonaware according to postconditioning interviews, but also by assessing their knowledge during the course of the conditioning. This made it possible to determine approximately when during the trial sequence subjects became aware of the CS-UCS relations, and whether differential conditioning 
appeared thereafter but not before. The only reported experiment pertaining to this issue is one by Hilgard et al. (1937). Using intertrial reports during the course of differential eyelid conditioning, they concluded that "the ability to state the stimulus sequences in words early in the experiment appears to be associated with ease of discrimination. .." (p.580). Conduct of their study deviated sufficiently from current experimental standards to warrant a reexamination of the problem.

The third purpose of the present study was to determine whether differential SCR conditioning could be demonstrated during differential eyelid conditioning. Assuming such an outcome, the intention was to compare the eyelid and SCR conditioning performance of subjects differing in awareness as revealed in postconditioning reports. In addition, the availability of intertrial reports made it possible to assess the coincidence during the trial sequence of awareness of the stimulus relations and conditioning in each of the two response modalities.

\section{METHOD}

The subjects were 51 paid male volunteers, ages $18-25$ years, recruited from local employment agencies and universities. All subjects were administered 80 differential eyelid conditioning trials. The CSs consisted of the $1,200-\mathrm{msec}$ illumination of slides containing either grammatically correct or grammatically incorrect two-word phrases previously used by Perry et al. (1977). The phrases consisted of either the word "one" or the word "two" followed by 1 of 20 common nouns in either singular or plural form. Examples of the four types of phrases are: "one tree," "two girls," "one cats," and "two table." The nouns were selected by Perry et al. (1977) from lists of "highimagery" words published by Paivio, Yuille, and Madigan (1968). On the basis of random assignment, half the subjects had grammatically correct phrases as the CS+ and half, incorrect phrases. Two schedules for administering trials were used, the order of phrases being unsystematic, with the constraints that blocks of 10 trials each contain five CS+ and five CS - phrases and that no more than three correct or incorrect phrases appear in succession. Similar to Perry et al. (1977), the CS-UCS interval was $1,000 \mathrm{msec}$ and the UCS was a 200-msec 3-psi corneal air puff that was presented on $80 \%$ of the CS+ trials. Intertrial intervals averaged $20 \mathrm{sec}$, with a range of $16-24 \mathrm{sec}$. The slides were projected (Kodak Carousel) from a location outside the sound-attenuated subject booth (AIC Model 402A) on a $45 \mathrm{x}$ $30 \mathrm{~cm}$ screen located approximately $1.5 \mathrm{~m}$ in front of the subject, slightly below eye level. Eyelid responses were recorded using a microtorque potentiometer attached to a headset on which an air jet delivery of the UCS also was mounted. Eyelid responses and their first derivatives were recorded on two channels of an oscillograph (Beckman Type R) and were scored according to procedures developed by Ross (Note 1 ). The SCRs were recorded by a bipolar constant-voltage $(.5 \mathrm{~V})$ method using silver/silver chloride electrodes (Menner-Greatbach) $.28 \mathrm{~cm}$ in area. The electrodes were filled with gel containing $.1 \mathrm{NaCl}$ and were taped to the palmar surface of the second and third phalanges of the third digit of the left hand. A reference electrode, $10 \times 8 \mathrm{~cm}$, was coated with gel and taped to the ventral surface of the left forearm.

Following each block of 10 trials, the subjects were asked to report regarding the experiment. Instructions for reporting were to the effect that subjects should comment on what they were observing, thinking, or feeling about events occurring in the experiment. Periodic intertrial reporting is relatively less sensitive to the development of awareness than is trial-by-trial reporting, since the initial awareness of the stimulus relations can occur during or following any trial within the 10-trial block but cannot be reported until its end. Trial-by-trial reporting was rejected because there would have been 80 reports, resulting in considerable lengthening of the average intertrial interval and producing unjustifiably long sessions. It was conjectured further that the length of the session and the repetitive nature of the many reports would have led to excessive boredom and loss of the subjects' cooperation. The subjects also underwent a postconditioning interview adapted from one described by Fuhrer and Baer (1969).

The verbal data were content analyzed by three raters who worked independently without knowledge of the subjects' conditioning performance. Based upon the ratings of the postconditioning interviews, each subject was classified as having accurately or inaccurately verbalized the CS-UCS relations. The guidelines for the ratings and for the classification of subjects also have been described by Fuhrer and Baer (1969). The intertrial reports were similarly analyzed by raters who did not know the interview results.

There was almost complete agreement between the two kinds of ratings. Of the 32 subjects whose postconditioning interviews qualified them as accurate verbalizers, only 3 did not verbalize the stimulus relations accurately during the intertrial reports. All 19 subjects whose interviews led them to be classified as inaccurate verbalizers failed to report accurately between trials.

The subjects also were identified as being either $V$-or $C$-form eyelid responders (Ross, Note 1). They were classified as V-form responders if $50 \%$ or more of their CRs had derivative amplitudes that equaled or exceeded the mean derivative amplitude of the first five UCRs for which there was no CR. All other subjects were identified as $\mathrm{C}$-form responders.

Three conditioning measures were analyzed: (1) the percentage of conditioned blinks to the CS+ and the CS - per trial block, each containing five CS - trials, four CS+ trials, and one CS+ test trial; (2) the percentage of conditioned blinks occurring on test trials; and (3) the square root of the amplitude in micromhos of SCRs appearing during test trials and during the CStrial preceding each test trial. Only SCRs originating 1-5 sec following CS onset were scored. Each SCR was measured from its onset to its peak. The smallest response amplitude that could be recorded was .03 micromhos. If multiple responses occured within the measurement interval, their amplitudes were summed prior to the square-root transformation.

\section{RESULTS}

Analyses of variance were composed of three variables, accurate vs. inaccurate verbalizers, CS+ vs. CS-, and trial blocks. A statistical significance level of .05 was used throughout. When the reliability of differential conditioning was assessed by means of a $t$ test, a one-tailed test was used. There was significant differential eyelid conditioning for the entire group of subjects based on the percentage of conditioned eyelid responses per trial block $[F(1,49)=9.45]$. Further, the extent of differential eyelid responding differed significantly between the subgroups of accurate and inaccurate verbalizers $[F(1,49)=8.25]$. It can be seen in Figure 1 that the accurate verbalizers showed substantial differential eyelid conditioning, whereas inaccurate verbalizers showed no consistent differentiation. A significant trial blocks effect also was obtained $[F(1,343)=12.4]$, reflecting a growth function for eyelid responding. 

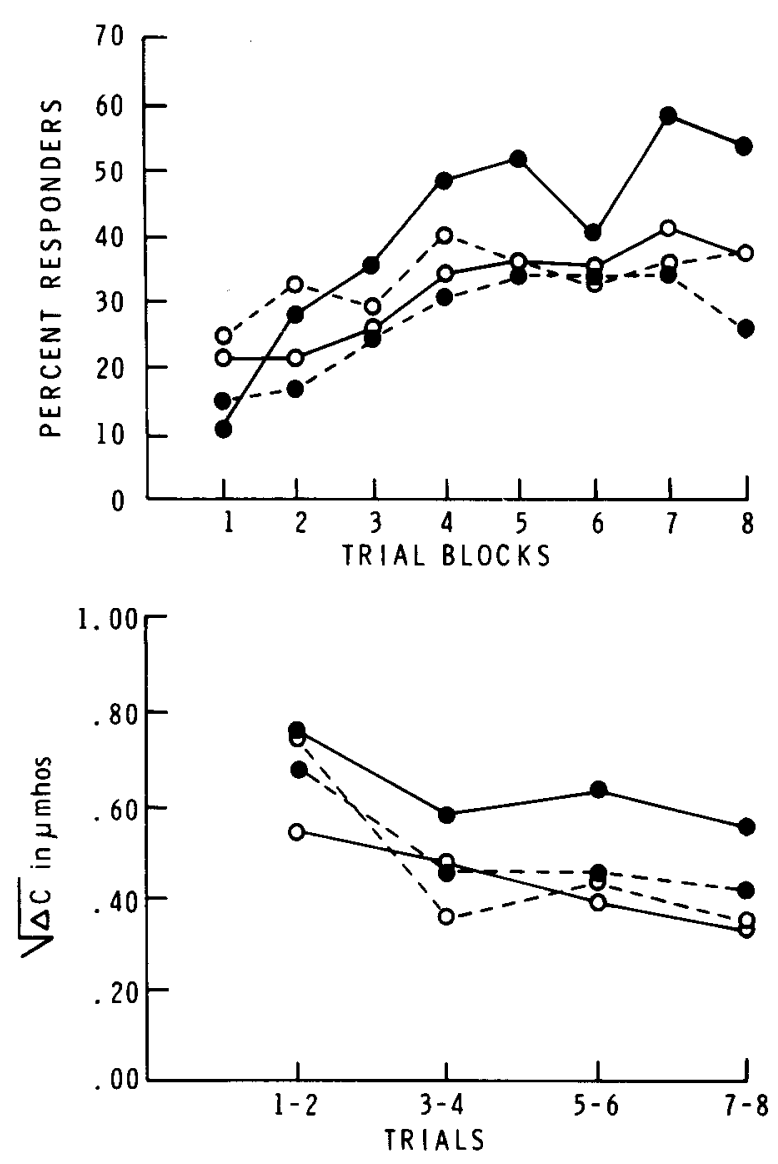

Accurate Verbalizers $\mathrm{N}=32$

$\mathrm{CS}+\longrightarrow \mathrm{CS}-\mathrm{C}-\mathrm{-}$

Inaccurate Verbalizers $\mathrm{N}=19$

$\mathrm{CS}+\mathrm{O}-\mathrm{CS}-\mathrm{O}--$

Figure 1. Mean percent eyelid responses (upper) and SCR magnitudes (lower) to the CS+ and CS- for accurate verbalizers and inaccurate verbalizers.

Results for the percentage of differential eyelid responses occurring on test trials duplicated those described for the percentage of responses per trial block and are not reported.

Significant differential conditioning of SCRs was not obtained for the entire group of subjects. It was found, however, that the subgroups of accurate and inaccurate verbalizers differed in the extent of SCR conditioning $[F(1,49)=5.49]$. As indicated in Figure 1, accurate verbalizers conditioned, but inaccurate verbalizers did not.

There were 18 accurate and 10 inaccurate verbalizers in the subgroup of V-form eyelid responders, and, respectively, 14 and 9 in the subgroup of $\mathrm{C}$-form eyelid responders. Although relatively more $\mathrm{V}$-form responders reported the CS-UCS relations correctly, the proportions of accurate and inaccurate verbalizers in the two subgroups did not differ significantly. The differential conditioning results for both $\mathrm{V}$ - and $\mathrm{C}$-form responders during the terminal trial block for both eyelid responses and SCRs are shown in Figure 2. There was a significant difference in the extent of differential eyelid conditioning $[F(1,26)=3.76]$ and of differential SCR conditioning $[F(1,26)=5.57]$ between the accurate and inaccurate verbalizers within the subgroup of $\mathrm{V}$-form responders. For the subgroup of $\mathrm{C}$-form responders, there was also a significant difference between accurate and inaccurate verbalizers for differentiation of conditioned eyelid responses $[F(1,21)=4.71]$, but not for SCRs. However, the extent of SCR differentiation among accurate verbalizers was significant $[t(13)=2.34]$. Inaccurate verbalizers, whether $\mathrm{V}$ - or $\mathrm{C}$-form responders, did not produce significant differentiation of either eyelid responses or SCRs. A comparison of accurate verbalizers in the $\mathrm{V}$-form and $\mathrm{C}$-form subgroups yielded no differences in the extent of differential conditioning for either of the two response measures. There was, however, a significant difference between the $\mathrm{V}$-form and C-form responders' eyelid responses to the CS+ and CS- combined $[F(1,30)=4.6]$, indicating greater eyelid responsivity for $\mathrm{V}$-form responders. A parallel finding was obtained for SCRs $[F(1,30)=5.3]$.

Two additional analyses concerned the relationship between differential conditioning and the initial intertrial report conveying recognition of the CS-UCS relations. In the first analysis, the differential conditioning performance of 18 accurate subjects was compared for trial blocks preceding and following a target trial block containing the first correct report of the stimulus relations. This analysis excluded the 13 subjects whose first accurate report followed the first trial block and the 1 subject whose first accurate report followed the eighth trial block. There was no evidence for differential conditioning in either response modality before the target trial block. Although neither SCRs nor eyelid response rates were significantly differentiated following the target trial block, both modalities showed tendencies toward differentiation in the expected direction.

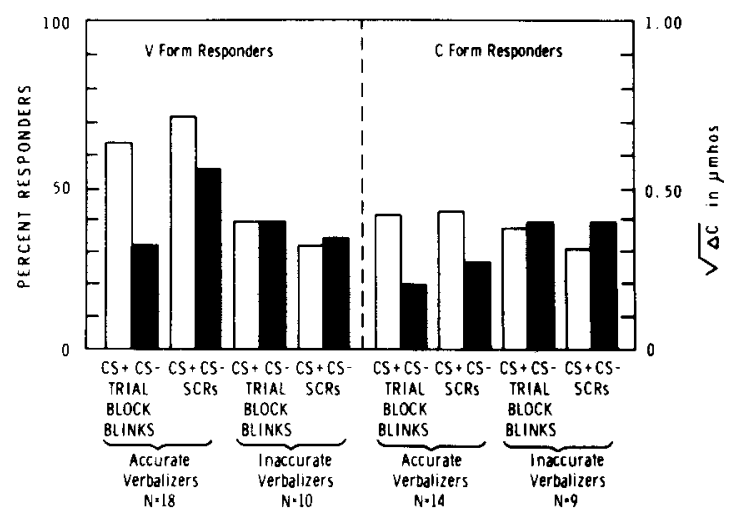

Figure 2. Mean percent eyelid responses and SCR magnitudes to the CS+ and CS - for accurately verbalizing and inaccurately verbalizing V-form responders (left) and C-form responders (right) during the eighth and last trial block. 


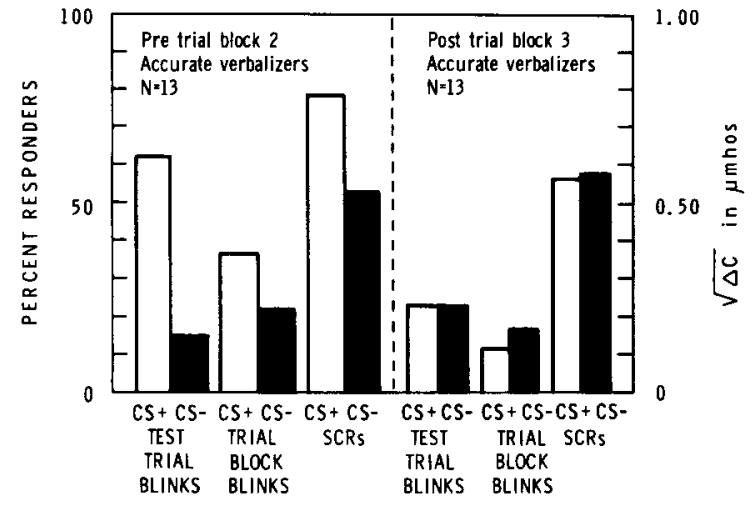

Figure 3. Mean percent eyelid responses and SCR magnitudes to the CS+ and CS- during Trial Block 2 for the 13 subjects who initially reported the stimulus relations accurately following the first trial block (left) and for the 13 subjects who initially reported accurately following the third trial block or later (right).



Figure 4. Mean percent eyelid responses and SCR magnitudes to the CS+ and CS-during Trial Block 8 for the 13 subjects who initially reported the stimulus relations accurately following the first trial block (left) and for the 13 subjects who initially reported accurately following the third trial block or later (right).

In a further analysis, the conditioning performance of the group of 13 subjects whose first correct report occurred prior to the second trial block was compared with that of the group of 13 subjects who first reported accurately following Trial Block 3 or later. The six subjects who first reported accurately following the second trial block were omitted from this analysis. The two groups were examined for the extent of differential conditioning during the second trial block. The data are depicted in Figure 3. For the group of early accurate verbalizers, there was significant eyelid conditioning for test trial responses $[t(12)=2.5]$, for total responses per trial $[t(12)=2.8]$, and for SCR conditioning $[t(12)=1.8]$. As Figure 3 indicates, no evidence of differential conditioning was demonstrated by subjects who verbalized later.

A final analysis was undertaken to determine whether the late verbalizers who first reported after the third trial block subsequently developed differential conditioning. Figure 4 shows the levels of differential responding for the groups of early and late verbalizers during the eighth and last trial block. The group of early verbalizers showed significant differential eyelid conditioning for responses on the test trial $[\mathrm{t}(12)=1.8]$, for total responses per trial $[t(12)=4.41]$, and for SCRs $[t(12)=2.1]$. The late verbalizers showed significant conditioning for SCRs [t(12) $=2.4$ ], but the difference between CS+ and CS- responsiveness was not significant for either of the measures of eyelid conditioning, although the results were in the expected direction. Since the proportions of C-and V-type responders in the subgroups of early and late accurate verbalizers did not differ, no analyses were undertaken in this regard.

\section{DISCUSSION}

Clear-cut evidence was obtained that differential eyelid conditioning performance was related to subjects' verbalized recognition of the CS-UCS relations. Replicating the findings of Perry et al. (1977), significant differential conditioning was limited to a group of subjects able to verbalize the stimulus relations accurately in the postconditioning interview. Conventional eyelid conditioning procedures, using simple, readily discriminable visual or auditory stimulis, militate against study of the awareness-conditioning relationship because so few subjects remain unaware. The present procedure involving grammatical correctness as a discriminandum may have distinctive merits for investigating this relationship. The word pairs that were used varied along several dimensions, including the singular or plural character of each word of the pair, the number of syllables in each word, the word meanings, and whether the word pair was grammatically correct or incorrect. Since only one of these dimensions was critical in distinguishing CS+ or CS- trials, availability of the irrelevant dimensions may have rendered the task sufficiently complex to prevent some subjects' recog. nizing the CS-UCS relations. Thus, by making the critical discrimination more difficult, the present procedure may have facilitated the attainment of results that otherwise depend on embedding the differential eyelid conditioning procedure in a masking task (e.g., Nelson \& Ross, 1974).

In the studies by Nelson and Ross (1974) and Perry et al. (1977), and in the present one, differential eyelid conditioning occurred among subjects aware of the stimulus relations, but unaware subjects did not show conditioning. The failure of inaccurate subjects to condition is probably not attributable to use of a complex CS dimension. In the Nelson and Ross (1974) study, in which simple unidimensional auditory CSs were used, unaware subjects did not condition. It also has been amply demonstrated that the use of simple CSs does not yield differential SCR conditioning among unaware subjects (Baer \& Fuhrer, 1968; Dawson \& Biferno, 1973).

By recording SCRs during the eyelid conditioning procedure, it was possible to demonstrate that the differential conditioning of electrodermal activity 
occurred in conjunction with the acquisition of differential eyelid CRs. A previously published demonstration of concurrent differential conditioning of both response modalities using a corneal air puff as the UCS could not be found. Although data for the total group of subjects did not reflect a reliable degree of differential SCR conditioning, a different picture emerged when the conditioning of subjects able to verbalize the stimulus relations accurately was separately assessed. Accurate verbalizers conditioned significantly, and inaccurate verbalizers did not. Previous studies yielding such results have depended almost exclusively upon noxious electrocutaneous stimulation as the UCS. The present findings suggest that a less noxious UCS, an avoidable air puff, is satisfactory for producing the same outcome. That a noxious UCS is unnecessary for differential SCR conditioning has also been demonstrated using a reaction time task as the UCS (Baer \& Fuhrer, 1969; Pendery \& Maltzman, 1977). The present results are distinctive in demonstrating that parallel conditioning in the two diverse modalities, autonomic and motor, is found only if the subject is aware of the stimulus relations.

In several important respects, comparative analyses of the performance of $\mathrm{V}$-form and $\mathrm{C}$-form eyelid responders yielded generally similar results. As found by Perry et al. (1977), the proportion of accurate and inaccurate verbalizers in each group did not differ significantly. This finding is not consistent with the suggestion that the $\mathrm{V}$-form responders are more analytic in formulating CS-UCS relations (Grant, 1972). The two subgroups exhibited a similar degree of eyelid conditioning, and within each subgroup, the extent of conditioning was associated positively with the subjects' awareness of the CS-UCS relations. These outcomes, too, are consistent with the results reported by Perry et al. (1977). The present findings suggest further that the two types of eyelid responders do not differ in terms of the differential conditionability of SCRs or in terms of the relation of awareness to conditioning in this modality. The $\mathrm{V}$ - and $\mathrm{C}$-form responders did differ in reactivity. Specifically, for analyses in which responses to the CS+ and CS- were combined, V-form responders were more reactive than C-form responders for both eyelid responses and SCRs. These findings are consistent with Grant's (1972) characterization of V-form responders as having a positive response tendency, and they extend this observation to an autonomic response modality.

Having subjects periodically report between trials made it possible to determine whether differential conditioning would occur only after the first report of awareness of the stimulus relations within the trial sequence. A subgroup of subjects who reported detecting the stimulus relations during the first trial block conditioned significantly in both response modalities during the second trial block, unlike another group of subjects who reported detecting the stimulus relations later.

These results are consistent with those reported by Biferno and Dawson (1977) for differentially conditioned SCRs. Biferno and Dawson's subjects also showed no differentiation preceding an intertrial indication of awareness of the stimulus relations, but they did so thereafter. When one examines conditioning curves of individual subjects, such as those provided by Pendery and Maltzman (1977) in a semantic conditioning situation, trial-by-trial changes in SCR amplitudes can be discerned that suggest a rapid onset of conditioning that contrasts with the smoother conditioning curves reflecting group averages. Pendery and Maltzman suggest that the variability of individual curves can be accounted for in part by referring to the subjects' thought processes during the experiment. This ideation may well be concerned with the CS-UCS relations.

A trial-by-trial link between awareness and conditioning was more prominent for SCRs than for eyelid responses. Subjects who reported awareness of the stimulus relations early during acquisition trials exhibited significant differential conditioning of both SCRs and eyelid responses in test trials occurring in the next trial block and in the last trial block as well. Subjects whose awareness developed relatively late in the trial sequence did not exhibit significant differential eyelid responding during the last trial block, although significant SCR differentiation was observed. The lack of eyelid response differentiation by the late-aware group was characterized more by attenuated responsiveness to the CS+ than to elevated responsiveness to the CS(Figure 4). The absence of differential conditioning performance by this group may have been due to simple conditioning effects that occurred prior to awareness. During these acquisition trials, the failure to discriminate the difference in contingencies between the CS+ and the CS- would have resulted in these stimuli serving, in effect, as a single CS that was being reinforced at a rate substantially less than $50 \%$. The inhibition of eyelid responding that presumably develops during such a low rate of reinforcement (Beecroft, 1966, p. 126) may have extended into the postaware trials to reduce responsiveness to the $\mathrm{CS}+$. Such a simple conditioning effect apparently did not interfere with SCR discrimination.

Alternatively, the failure of CSt responding to increase following awareness achieved late in the trial sequence may have been due to diminution of the perceived noxiousness of the air-puff UCS by virtue of its having been repeatedly experienced during the earlier trials, in which the anticipatory eyelid closure was either poorly timed or did not occur at all. The contrasting findings of significant SCR differentiation can be interpreted on the grounds that SCRs to the CS+ and the CS- are a component of the orienting response 
and that the noxiousness of the UCS is less important for the development of differential SCRs than for eyelid responses. In such terms, becoming aware of the signaling function of the CS+ and the nonsignal significance of the CS- may be more important than the noxiousness of the UCS and could have been sufficient to produce differential SCRs to the two stimuli. This view is substantiated by studies in which reliable differential conditioning of SCRs has been produced with a nonnoxious UCS, such as the signal to respond in a reaction time task (Baer \& Fuhrer, 1969; Pendery \& Maltzman, 1977).

\section{REFERENCE NOTE}

1. Ross, S. H. Eyelid scoring manual. Unpublished manuscript, University of Wisconsin, 1968.

\section{REFERENCES}

BaEr, P. E., \& Fuhrer, M. J. Cognitive processes during differential trace and delayed conditioning of the GSR. Journal of Experimental Psychology, 1968, 78, 81-88.

Baer, P. E., \& Fuhrer, M. J. Cognitive processes in the differential trace conditioning of electrodermal and vasomotor activity. Journal of Experimental Psychology, 1970, 84, 176-178.

Baer, P. E., \& Fuhrer, M. J. Cognitive factors in differential conditioning of the GSR: Use of a reaction time task as the UCS with normals and schizophrenics. Journal of Abnormal Psychology, 1969, 74, 544-552.

Beecroft, R. S. Classical conditioning. Goleta, Calif: Psychonomic Press, 1966.

Biferno, M. A., \& Dawson, M. E. The onset of contingency awareness and electrodermal classical conditioning: An analysis of temporal relationships during acquisition and extinction. Psychophysiology, 1977, 14, 164-171.

Dawson, M. E., \& Biferno, M. A. Concurrent measurement of awareness and electrodermal classical conditioning. Journal of Experimental Psychology, 1973, 101, 55-62.
Dawson, M. E., \& Furedy, J. J. The role of awareness in human differential autonomic classical conditioning: The necessity-gate hypothesis. Psychophysiology, 1976, 13, 50-53.

Fuhrer, M. J., \& BaEr, P. E. Cognitive processes in differential GSR conditioning: Effects of a masking task. American Journal of Psychology, 1969, 82, 168-180.

Grant, D. A. A preliminary model for processing information conveyed by verbal conditioned stimuli in classical conditioning. In A. H. Black \& W. F. Prokasy (Eds.), Classical conditioning II: Current research and theory. New York: Appleton-CenturyCrofts, 1972.

Grant, D. A. Cognitive factors in eyelid conditioning. Psychophysiology, 1973, 10, 75-81.

Hilgard, E. R., Campgell, A. A., \& Sears, W. N. Conditioned discrimination: The development of discrimination with and without verbal report. American Journal of Psychology, $1937,49,564-580$.

Kimble, G. A. Classical conditioning and the problem of awareness. In C. W. Eriksen (Ed.), Behavior and awareness. Durham, N.C: 1962.

Nelson, M. N., \& Ross, L. E. Effects of masking tasks on differential eyelid conditioning: A distinction between knowledge of stimulus contingencies and attentional or cognitive activities involving them. Journal of Experimental Psychology, 1974, $102,1-9$.

Paivio, A., Yuille, J. C., \& Madigan, S. A. Concreteness, imagery, and meaningfulness values for 925 nouns. Journal of Experimental Psychology, 1968, 76, 1-25.

Pendery, M., \& Maltzman, I. Instructions and the orienting reflex in "semantic conditioning" of the galvanic skin response in an innocuous situation. Journal of Experimental Psychology: General, 1977, 106, 120-140.

Perky, L. C., Grant, D. A., \& Schwartz, M. Effects of noun imagery and awareness of the discriminative cue upon differential eyelid conditioning to grammatical and ungrammatical phrases. Memory \& Cognition, 1977, 5, 423-429.

Shean, G. D. Vasomotor conditioning and awareness. Psychophysiology, 1968, 5, 22-30.

(Received for publication May 4, 1981; revision accepted December 14, 1981.) 